\title{
THE DEVELOPMENT OF THE GRAPHITE BARREL OF THE COAXIAL MAGNETOPLASMA ACCELERATOR
}

\author{
Ksenia Shatrova ${ }^{1 a}$, Alexander Pak $^{1}$, Elvira Sokolova ${ }^{1}$ \\ ${ }^{1}$ National Research Tomsk Polytechnic University, 634050 Tomsk, Russia
}

\begin{abstract}
The plasma accelerators are widely used for some powder and bulk (coatings) materials synthesis. Some metastable or high temperatures polymorphs require some special conditions for crystallization, for example ultra-high cooling rate. One of the possible ways to obtain these materials is the synthesis in a high speed plasma jet generating by a high current pulsed power plasma accelerator. The paper presents the results of experimental research concerning the development of a graphite barrel design of a high-current coaxial magnetoplasma accelerator. The developed design allows generating high-speed carbon electric discharge plasma jets with a pulse supply energy over $30 \mathrm{~kJ}$ by electrical power of about 140 MW.
\end{abstract}

\section{Introduction}

Recently, such materials as ultrafine tungsten carbide, carbon nitride and others have been found a wide application for power industry as catalysts for the hydrogen production from water and the hydrogen oxidation reaction [1-7]. Currently, many different methods for obtaining the materials are offered [8-14]. But synthesis process of these materials is complicated due to some special extreme conditions. For example cubic tungsten carbide is useful material for catalytic systems design and constructing. The synthesis process of this material requires ultra fast cooling rate for cubic lattice crystallization and stabilization. One of the devices used to carry out this process is a high-current pulsed coaxial magnetoplasma accelerator (CMPA). In particular, the possibility of obtaining crystalline phases in W-C-N system using CMPA is shown in papers [15-18]. It generates high-speed jets of carbon-containing electrical discharge plasma. During the plasma flowing the shock waves are generated and high temperatures and pressures are reached. Some materials have been synthesized by this process, however this method is experimental and the facilities need to be improved for the development of scientific and technical technology bases on it. The paper presents some experimental results concerning the development of the CMPA graphite barrel design. The developed design allows generating high-speed carbon electric discharge plasma jets with the pulse supply energy over $30 \mathrm{~kJ}$ by electrical power of about $140 \mathrm{MW}$.

\section{Experimental part}

a Corresponding author : shatrova.xiusha@yandex.ru 
CMPA is constructed in the form of a hybrid accelerating system based on the classical Z-pinch accelerator (pinscher) which is put in the external induction system. The pincher is composed of three basic elements: a central electrode, electrode barrel and case. A bridge (short) made of a carbon material (carbon black) is put in the plasma structure formation channel (PSFC) of high-current discharge in fiberglass insulator of the central electrode. It is the precursor for plasmodynamic synthesis. The weight of plasma jet material is composed of the material put in PSFC and the material eroded from the surface of the central electrode and an accelerating channel (AC). Assembled pinscher is installed in the external induction system. The assembled CMPA barrel is installed in a sealed reactor and is connected by a discharge circuit bus-bar of capacitive energy storage, as shown in figure 1.

The research of the development of the CMPA barrel with graphite accelerating channel was carried out to find the optimal construction (concerning maximum input energy) experimentally. The papers [15-18] describe the operating principle of the experimental facilities and consider thoroughly the possibility of crystalline material synthesis using it.

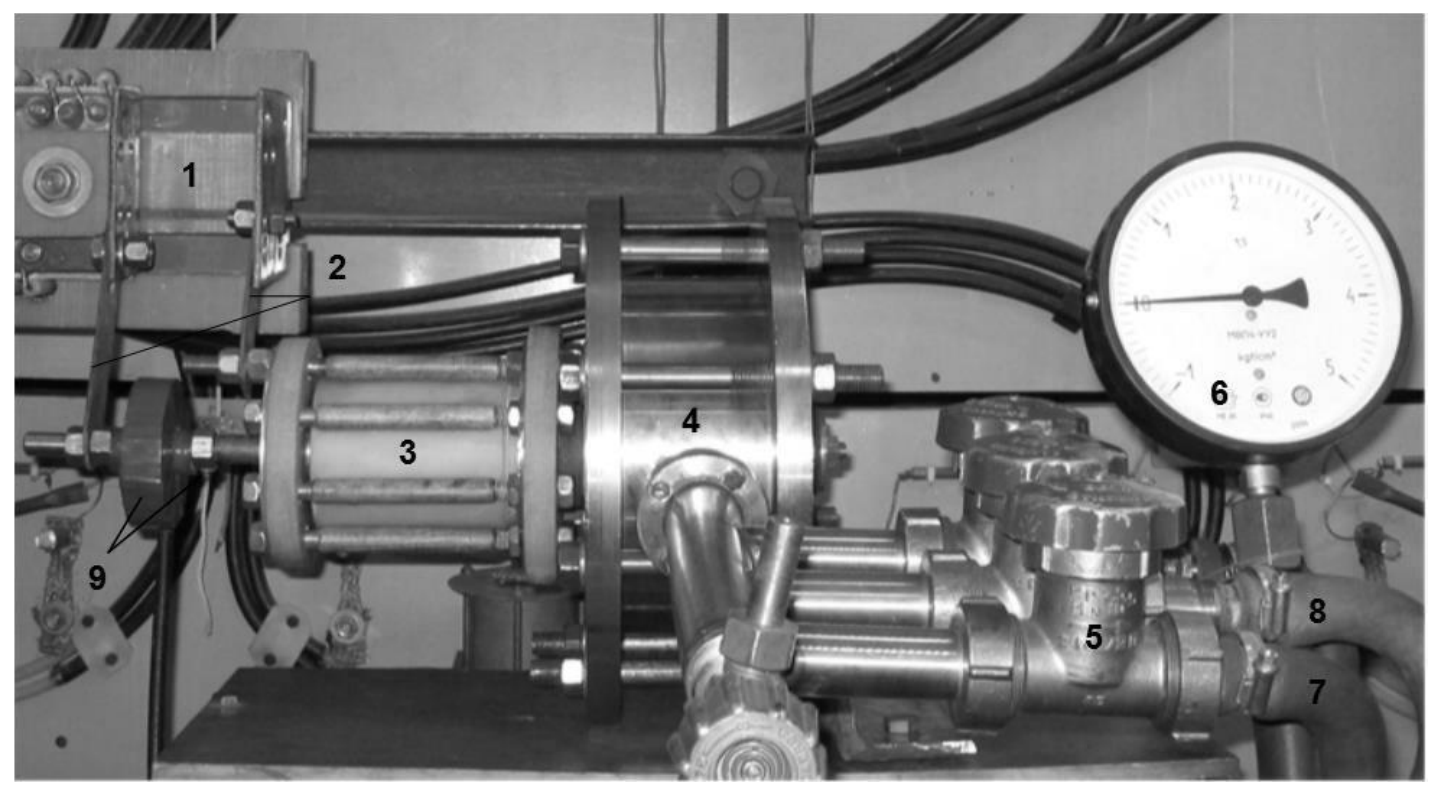

Figure 1. The experimental facility image: 1 - collector; 2 - supply line of CMPA; 3 - CMPA; 4 - chamber; 5 valve system; 6 - manometer; 7 - vacuum pump port; 8 - port of nitrogen cylinder; 9 -circuit of current and voltage recording

Two types of electrode accelerator system design were made to solve this problem. The first type of barrel is shown in figure 2 .

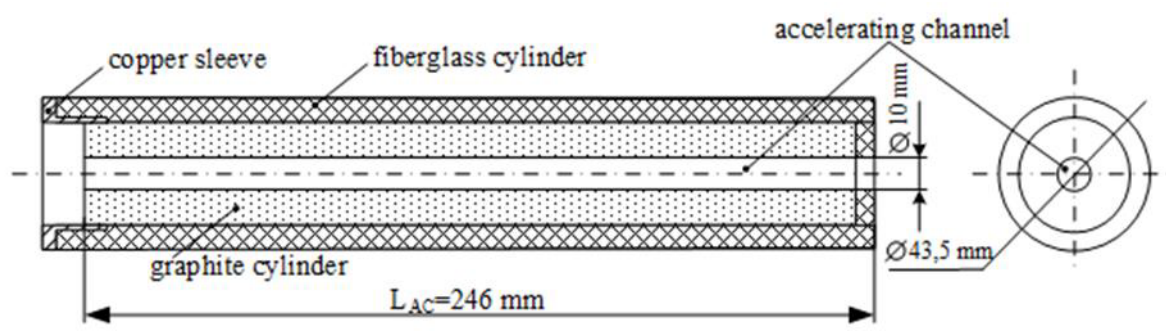

Figure 2. The first type of graphite barrel design 
The main element of the construction is a graphite rod with an axial cylindrical AC made of graphite MPG-8 (N). Its mechanical strength is provided by fiberglass bandage. Mechanical and electrical connection of the graphite cylinder with a conductive metal case of the central electrode unit is realized by a conducting metal sleeve (copper). One of a central failure of this design is the high longitudinal ohmic resistance of the electrode-barrel which is about $0.1 \mathrm{ohms}$. This high resistance reduces the efficiency of energy conversion according to the mechanism of the conductive electrodynamics. The removal of this disadvantage is achieved by using copper strip guides. These guides contact with a graphite cylinder throughout the outside length, as shown in figure 3 , which shows the second version of the accelerator stem. The copper guides allowed a two-order stem longitudinal resistance reduction. The comparative experiments using two types of stems were carried out at $\mathrm{C}=12 \mathrm{mF}$ capacity of power supply; charging voltage $\mathrm{Uin}=3.0 \mathrm{kV}$, the inductance of the discharge circuit (including the accelerator) up to $1 \mu \mathrm{H}$. Plasma flowed into the reactor filled with nitrogen (normal conditions).

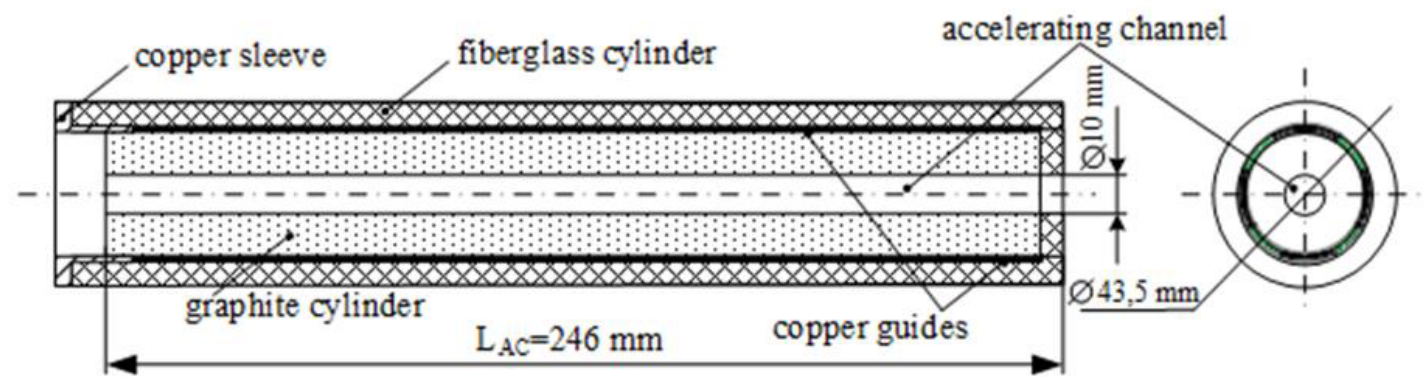

Figure 3. The second type of graphite barrel design

\section{Results and discussions}

Oscillograms of current and voltage recorded in the process of CMPA work, the calculated curves of power as well as released energy are shown in figure 4 and 5.

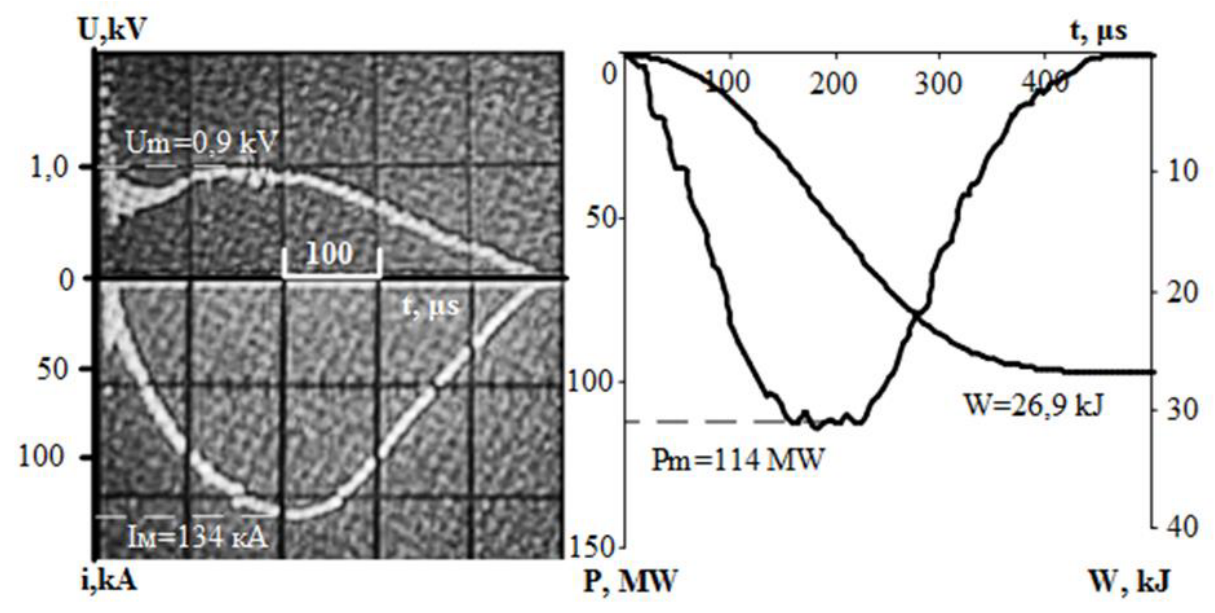

Figure 4. Oscillograms of current and voltage recorded in the process of CMPA work, the calculated curves of power and released energy using barrel design without copper guides 


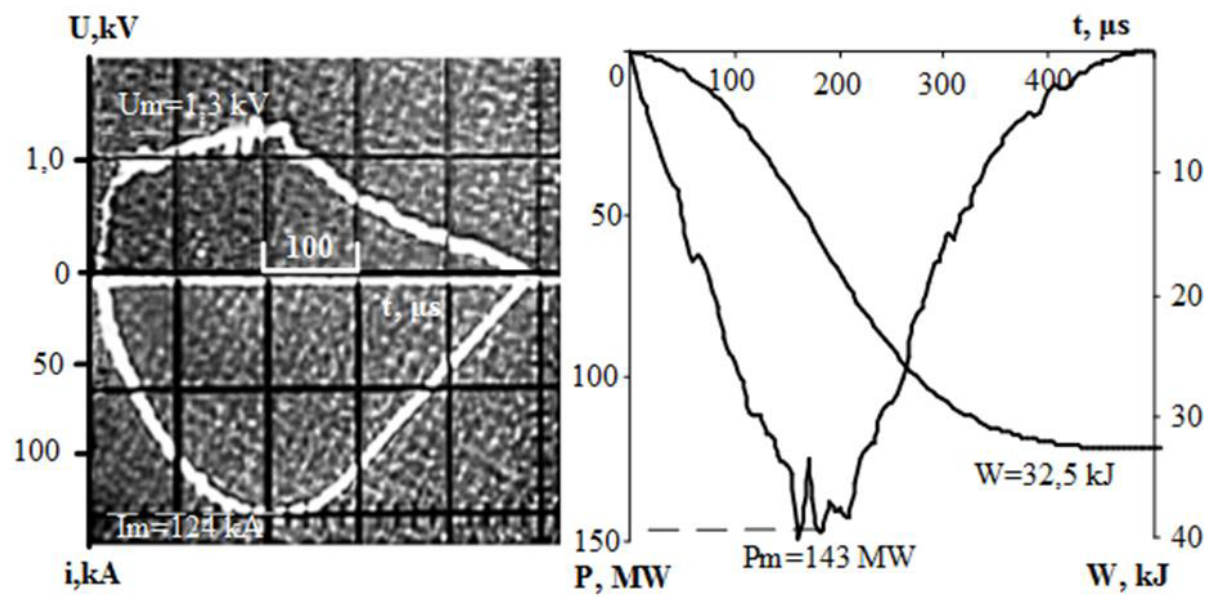

Figure 5. Oscillograms of current and voltage recorded in the process of CMPA work, the calculated curves of power and released energy using barrel design with copper guides

According to the oscillograms and calculated curves the use of graphite barrel with copper guides provides higher $\mathrm{dU} / \mathrm{dt}$, voltage rise of arc discharge stage Um and some natural decrease of the amplitude value of current Im. The development of higher power Pm = 143.1 MW leads to the increase of energy consumption of accelerator $\mathrm{W}$ and its specific values per unit volume of the AC $\mathrm{W} / \mathrm{V}=1,89 \mathrm{~kJ} / \mathrm{cm} 3$ compared with the use of a barrel without copper guides: $\mathrm{Pm}=113.9 \mathrm{MW}, \mathrm{W}=$ $26,9 \mathrm{~kJ}$ and $\mathrm{W} / \mathrm{V}=1,57 \mathrm{~kJ} / \mathrm{cm} 3$. As a result, the use of longitudinal copper guides allowed to increase the speed of the bow shock ( $\mathrm{Vc}$ ) on a section of the AC from $1.98 \mathrm{~km} / \mathrm{s}$ to $2.25 \mathrm{~km} / \mathrm{s}$, that is $13.6 \%$ higher. In our opinion this is due to the increase in the "active" length of the AC [19], where steady state discharge of Z-pinch type is retained. The efficiency of the electrodynamic Lorentz force improves in the coaxial system of the coaxial railotron type [20].

$$
F_{x}=\frac{L^{\prime} I^{2}}{2}
$$

where $L^{\prime}=\frac{d L}{d l}$ is running inductance of acceleration system.

Furthermore, such barrel design with longitudinal guides shields minimally [19] the AC volume due to the relatively high azimuthal resistance of the graphite barrel as short-circuited turn, providing the penetration of axial field of the solenoid of the induction system in the AC.

However, all mentioned above advantages of the barrel structure (figure 3) don't compensate for the significant lack of low mechanical strength. Under the action of ultrahigh pulsed pressure, occurring in the $\mathrm{AC}$, the deformation of the fiberglass cylinder and some longitudinal cracks of the graphite cylinder are made. At $\mathrm{W} \approx 30,0 \mathrm{~kJ}$ barrel resource is reduced to one plasma shot and there is not only eroded carbon, but also quite large graphite particles in the product. It complicates the analysis of the product of synthesis and requires its purification, which can have an influence on the synthesized phase. 


\section{Conclusion}

This paper presents the results of the design of a graphite barrel of the high current pulsed power coaxial magneto plasma accelerator. The paper shows that the graphite barrel with copper guides is the optimal variant due to the ability to maintain the highest values of plasma speed and energy input. This barrel design allows to reduce the longitudinal ohmic resistance and increase the efficiency of the plasma accelerator operating mode. However, the mechanical properties of the designed construction and its reliability require some improvements. This issue is the reason to keep on the research.

This work was supported by the Russian Federation President's fellowship for PhD students and young PhD holders. This work was supported by the program (project VIU ENIN 94 2014) to improve the competitiveness of National Research Tomsk Polytechnic University.

The authors heartily thank scientific adviser professor A. A. Sivkov from Tomsk Polytechnic University (Department of Industrial Electric Power Supply of Institute of Power Engineering).

\section{References}

1. D.J. Ham, R. Ganesan, J.S. Lee, Int. J. Hydrogen Energy, 33, 6865 (2008)

2. Y. Zhu, Y. Xu, Y. Hou, Z. Ding, X. Wang, Int. J. Hydrogen Energy, 39, 11873 (2014)

3. H. Yan, Y. Chen, Sh. Xu, International Journal of hydrogen energy, 37, 125 (2012)

4. A. Thomas, A. Fischer, F. Goettmann, M. Antonietti, J.-O. Muller, R. Schlogl, J.M. Carlsson, J. Mater. Chem., 18, 4893 (2008)

5. M. Kim, S. Hwang, J.-S. Yu, J. Mater. Chem., 17, 1656 (2007)

6. J. Kim, J.-H. Jang, Y.-H. Lee, Y.-U. Kwon, J. Power Sources, 193, 441 (2009).

7. V.M. Nikolic, D.L. Zugic, I.M. Perovic, A.B. Saponjic, B.M. Babic, I.A. Pasti, M.P.M. Kaninski, Int. J. Hydrogen Energy, 38, 11340 (2013)

8. A.S. Kurlov, A.I. Gusev, Russ. Chem. Rev., 75, 617 (2006)

9. H. Singh, O.P. Pandey, Ceram. Int., 39, 6703 (2013)

10. S. Aravinth, B. Sankar, M. Kamaraj, S.R. Chakravarthy, R. Sarathi, Int. J. Refract. Met. Hard Mater., 33, 53 (2012).

11. W.-H. Chen, P.K. Nayak, H.-T. Lin, M.-P. Chang, J.-L. Huang, Int. J. Refract. Met. Hard Mater., 47, 44 (2014).

12. I. Widlow, Y.-W. Chung, Int. Mater. Rev., 47, 153 (2002).

13. M. Sougawa, T. Sumiya, K. Takarabe, Y. Mori, T. Okada, H. Gotou, T. Yagi, J. Phys.: Conf. Ser., 215, 1 (2010).

14. G. Goglio, D. Foy, G. Demazeau, Materials Science and Engineering R, 58, 195 (2008).

15. A. Sivkov, A. Pak, I. Shanenkov, J. Kolganova, K. Shatrova, IOP Conference Series: Materials Science and Engineering, 66, 1 (2014).

16. A.Y. Pak, A. Sivkov, I. Shanenkov, I. Rahmatullin, K. Shatrova, Int. J. Refract. Met. Hard Mater., 48, 51 (2015).

17. A.A. Sivkov, E.P. Naiden, A.Y. Pak, Journal of Superhard Materials, 31, 300 (2009).

18. A.A. Sivkov, A.Y. Pak, Tech. Phys. Lett., 37, 654 (2011).

19. D.Yu. Gerasimov, A.A. Sivkov, J. Appl. Mech. Tech. Phys., 53, 140 (2012).

20. M.F. Zhukov, Institute of Thermophysics SD AS USSR, Novosibirsk, (1990). 